\title{
A Holy Quran Reader/Reciter Identification System Using Support Vector Machine
}

\author{
Khalid M. O. Nahar, Moyawiah Al-Shannaq, Ahmad Manasrah, Rafat Alshorman, and Iyad Alazzam
}

\begin{abstract}
Holy Quran Reader Identification is the process of identifying the reader or reciter of the Holy Quran based on several features in the corresponding acoustic wave. In this research, we build our own corpus, which contains 15 known readers of the Holy Quran. The Mel-Frequency Cepstrum Coefficients (MFCC) are used for the extraction of these features from the input acoustic signal. These MFCCs are the reader's features matrix, which is used for recognition via Support Vector Machine (SVM) and Artificial Neural Networks (ANN). According to our experimental results, the Holy Quran Reader Identification System identifies the reader with 96.59\% accuracy when using SVM, in contrast to accuracy of $86.1 \%$ when using ANN.
\end{abstract}

Index Terms-Reader identification, feature extraction, Mel-Frequency Cepstrum Coefficients (MFCC), support vector machine (SVM), Artificial Neural Networks (ANN).

\section{INTRODUCTION}

The process of reader identification is a general process that covers a wide area in voice recognition systems. For instance, the reader identification process uses the reader's voice as a biometric signal to recognize an individual's identity from the underlying speech information. The process of reader identification can be used for a broad range of applications such as forensic tests, automatic indexing of speech databases, voice dialling, and in enhancing speech recognition systems, among others. However, although there have been numerous efforts to increase the accuracy of such systems, the identification process still lacks the accuracy required in the recognition of voices, especially in noisy environments.

Generally, speaker recognition applications can be divided into speaker identification and speaker verification categories Speaker identification determines the identity of an anonymous speaker based on the his/her utterances. On the other hand, speaker verification verifies the speaker's identity from his voice characteristics [1]. Speaker recognition usually requires the speaker to say the same utterance as a text-dependent identification system, or without speech constraints as a text-independent identification system. Over the past few decades, significant research has been conducted to improve text-independent speaker identification performance in terms of accuracy and

Khalid M. O. Nahar, Moyawiah Al-Shannaq, Ahmad Manasrah, Rafat Alshorman are with Department of Computer Sciences, Faculty of IT and Computer Sciences, Yarmouk University, Irbid, 21163, Jordan (Corresponding author: Khalid M. O. Nahar; e-mail: khalids@yu.edu.jo).

Iyad Alazzam is with Department of Computer Information System, Faculty of IT and Computer Sciences, Yarmouk University, Irbid, 21163, Jordan. systems robustness, special conditions where there, they are noise and vibration. The research in this field focuses on converting a caustic wave form into features that are useful for further processing to identify the owner. The strength of the state-of-the-art algorithms used depends on the features' capability of capturing time frequency and energy into a set of coefficients for cepstrum analysis [2]. Several studies have achieved promising results in identifying the speakers from acoustic waves by using different extraction methods and classification schemes such as those based on vector quantization [3], the Gaussian mixture model [4]-[6] and Gamma Tone Frequency Cepstral Coefficients (GFCC) with I-vectors [7], [8]. It is, however, important to extract features from each frame to capture speaker characteristics. Features such as the Mel-frequency cepstral coefficients (MFCC) [9], [10] and perceptual linear predictive (PLP) coefficients [11], [12] are commonly adopted for speaker identification and recognition algorithms.

The human voice conveys a great deal of information such as the gender, emotions, and identity of the speaker, which is converted into a digital signal to produce digital data representing each level of signal at every discrete time step [13]. The digitized speech samples are converted into the Mal-Frequency Cepstrum Coefficient (MFCC) to produce the features of the wave vectors, which can be then used in learning algorithms such as SVM, and ANN. Even though most of the known acoustic-property-based algorithms have achieved an almost 100\% level of accuracy in an uncluttered environment [14], [15], the performance of these algorithms is degraded with channel variations due to the microphones, used or environmental or background distortions [14].

In this paper, a Holy Quran reader/reciter identification model is proposed. Unlike any other voice or speaker identification system, the voices of the readers who recite the Holy Quran and the way they do so is very different from the voice and delivery of ordinary speech. The difference is due to the existence of certain acoustic rules, known as "Ahkam Al Tajweed" "أحكام التجويد", that must be applied when reading the Holy Quran aloud. X). Furthermore, emotional features, which are added by the reader, as well as the transition from one pitch or tone to another when reading the Holy Quran distinguish such readings from normal speech.

The transition from one pitch to another is known as Maqam (مقام). This very important feature must be maintained while reciting the Holy Quran. As a result, the proposed model converts the readers' sound waves into MFCC to extract the feature vector matrix. The proposed model has been practiced and tested using both SVM and ANN. SVM is widely used and has proved to be effective for speaker recognition [16].

This paper also contains a related work in Section II. the Methodological steps and algorithm are presented in Section 
III, while Section IV illustrates the results of the experiments. Section V concludes the paper and sheds light on future research potential.

\section{RELATED WORK}

The nature of the recitation of the verses of the Holy Quran is different from that of any other type of speech or utterance. To date, to our knowledge, no one has addressed the area identifying the speech of Holy Quran readers., which is not true of other types of voice and speaker identification systems. Different approaches exist in the literature for using the MFCC features along with some learning algorithms such as the Hidden Markov Model (HMM), SVM, and ANN among others. One example, [2], is the design of a small-scale system for speaker and speech recognition with specific visual information for the user. Through the HMM, the authors successfully recognized isolated words where the speech recognition was achieved through extracting a set of feature vectors using MFCC. The Vector Quantization (VQ) was used for the practice and classification of the features. The accuracy of discrete speaker and/or speech recognition was $90 \%$ over a database of recorded voices. Likewise, [17] a further example presented a real time speaker recognition system using MFCC and VQ. This research was evaluated with 120 speakers with a TIDIGIT database. The proposed real time system uses the LBG algorithm proposed in a further example [18] to group

the set of acoustic vectors into sets of codebook vectors. The experimental results showed $91 \%$ accuracy in normal environmental conditions at 20db SNR.

However, the proposed system was tested and assessed using a sample of only seven speakers. This limitation can be addressed through other matching techniques such as HMM and delta spectral Cepstrum coefficient as suggested by the authors. Similarly, [19] a proposed voice recognition approach based on MFCC features and SVM learning algorithm for speaker identification is suggested. The proposed approach was practiced over a database of eight speakers/readers. The feature vectors were extracted using MFCC from the input speech. The feature vectors are used as the speaker features for learning and matching using SVM. The accuracy rate reached was $95 \%$. This result suggests the use of ANN or GMM techniques to improve performance and increase accuracy.
Each language has its own phonetic system. The Arabic sound system, which is different from the English sound system, has a unique phonetic structure as each spoken word has a phonetic combination of certain sound units. Therefore, various scholars have proposed methods for an Arabic -based speaker or voice recognition system. For instance, a new feature called Multi Directional Local Features (MDLF) was suggested and applied on automatic speaker recognition [20]. The MDLF showed significant improvements compared to conventional features. The authors also focused on how to select optimum features from a 48- dimensional MDLF to increase the speaker recognition rate and the possibility of applying the MDLF features to Arabic speech recognition systems. In Arabic, some authors like the one in [21] suggested that knowing the length of a specific phoneme can assist in speeding up the recognition process as well as increasing recognition accuracy. As a result, the authors have presented a statistical study and analysis of the Arabic phonemes. They have also utilized the previous assumption, that knowing the length of a specific phoneme would be helpful, to limit the length of an HMM chain to increase recognition accuracy. They have also improved the manner of searching for phonemes through adopting the median length of each cluster during the recognition phase. However, the proposed statistical analysis requires manual tuning of the recognition and configuration rates for building the best acoustic model.

Since the voice is a signal of infinite information, direct analysis and synthesizing of the complex voice signal is required. To represent the voice signal, various Feature Extraction and Feature Matching algorithms are introduced. Therefore, [13] based on an assumption that the voice signal may have different temporal rates, they propose a non-parametric method for modelling the human auditory perception system. They utilize the MFCC as a feature extraction technique along with the non-linear sequence alignment known as Dynamic Time Warping (DTW) as a feature- matching techniques. The proposed method proved to be an efficient voice recognition algorithm. However, with constant window spacing, the lengths of the input and stored voice signals are unlikely to be the same. Moreover, there will be a variation in the length of individual phonemes that has not been addressed in the proposed method.

Table I summarizes some of the studies which have addressed speaker identification in their research.

TABLE I: LITERATURE SUMMARY

\begin{tabular}{|c|c|c|c|c|}
\hline Author/year & Highlights & $\begin{array}{l}\text { No. of } \\
\text { Speakers }\end{array}$ & Database & Recognition rate \\
\hline $\begin{array}{l}\text { (Das and Nahar, } \\
\text { 2016) }\end{array}$ & $\begin{array}{l}\text { Hidden Markove Model (HMM) to recognize isolated word, Mel } \\
\text { Frequency Cepstral Coefficients (MFCC) and (VQ) for speech } \\
\text { recognition using MATLAB. }\end{array}$ & 40 & $\begin{array}{l}\text { Three hours of } \\
\text { news recordings }\end{array}$ & $\begin{array}{l}\text { speech recognition has been successfully } \\
\text { accomplished with about } 90 \% \text { accuracy }\end{array}$ \\
\hline (Bharti, 2015) & $\begin{array}{l}\text { Mel Frequency Cepstrum Coefficient (MFCC) and Vector } \\
\text { Quantization (VQ) using MATLAB. }\end{array}$ & $\begin{array}{l}120+5 \\
\text { local }\end{array}$ & TIDIGIT database & $\begin{array}{l}\text { The experimental results showed } 91 \% \\
\text { accuracy in normal environmental } \\
\text { conditions at } 20 \mathrm{db} \text { SNR }\end{array}$ \\
\hline $\begin{array}{l}\text { (Nijhawan and } \\
\text { Soni, 2014) }\end{array}$ & $\begin{array}{l}\text { Support Vector Machine (SVM) for speaker identification and } \\
\text { feature extraction by using (MFCC). }\end{array}$ & 8 & local & the accuracy rate is $95 \%$ \\
\hline $\begin{array}{l}\text { (Alsulaiman } e t \\
\text { al., 2017) }\end{array}$ & $\begin{array}{l}\text { A new feature called Multi Directional Local Features (MDLF) is } \\
\text { proposed and applied on automatic speaker recognition. }\end{array}$ & 49 & TIMIT database & $\begin{array}{llr}\text { (MDLF) } & \text { showed } & \text { significant } \\
\text { improvements } & \text { compared to MFCC and } \\
\text { LF } & \end{array}$ \\
\hline $\begin{array}{l}\text { (Nahar et al., } \\
\text { 2012) }\end{array}$ & $\begin{array}{l}\text { A statistical study and analysis of Arabic phonemes designed to } \\
\text { improve the performance of current ASR systems. }\end{array}$ & 40 & $\begin{array}{l}\text { Three hours of } \\
\text { news recordings }\end{array}$ & $\begin{array}{l}\text { increase the speed of the clustering of the } \\
\text { phonemes and increase the recognition } \\
\text { accuracy }\end{array}$ \\
\hline $\begin{array}{l}\text { (Linde } \text { et al., } \\
\text { 1980) }\end{array}$ & $\begin{array}{l}\text { The use of MFCC and DTW) to increase the voice recognition } \\
\text { performance. }\end{array}$ & 2 & Local & $\begin{array}{l}\text { the results show that these techniques } \\
\text { could be used effectively for voice } \\
\text { recognition }\end{array}$ \\
\hline
\end{tabular}


In our research we focus on identifying the reader name by exploring his vocal features, which is considered as a challenge in voice recognition systems. Identifying Holy Quran reciter or reader is not like identifying a normal speaker, since the original voice of Holy Quran reciter will not be as is, it is governed by "Ahkam Al Tajweed" " أحكام "التجويد". Identifying the person name through his vocal features is one of the main objectives of via voice systems. Sometimes we may find some audio files without any annotation, for example Holy Quran Audio files with unknown reader. It is beneficial to know the reader or reciter name of this files, else we should mark them as unknown reader. In our research we contribute in the direction of annotating unannotated Holy Quran audio files by the corresponding reciter. As mentioned before SVM is widely used and has proved to be effective for speaker recognition [16].

\section{THE PROPOSED APPROACH}

The speaker recognition's main components are feature extraction, and speaker modelling. Fig. 1 illustrates an overview of the proposed identification system. The proposed system mainly consists of practice and testing phases.

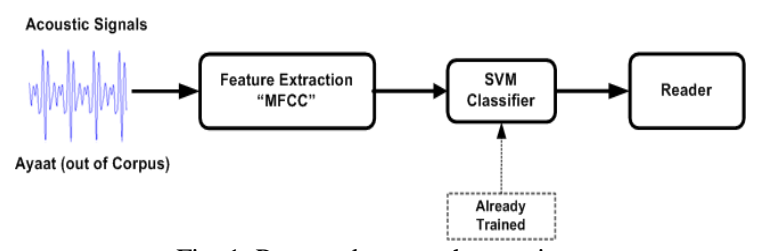

Fig. 1. Proposed approach overview.

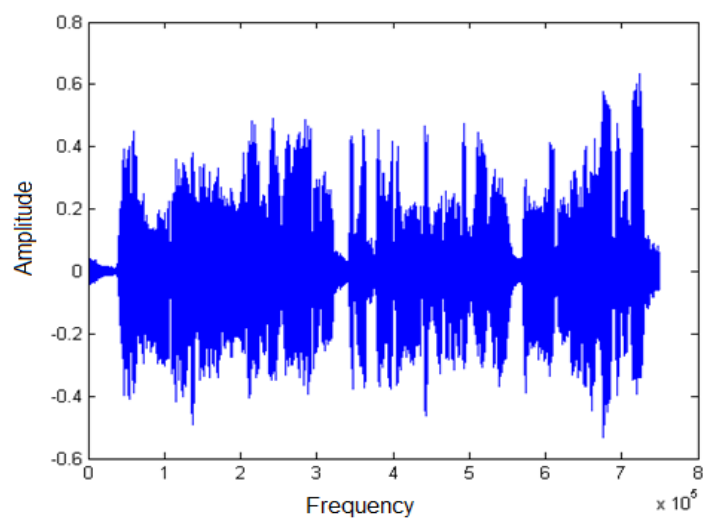

Fig. 2. Sample of acoustic wave.

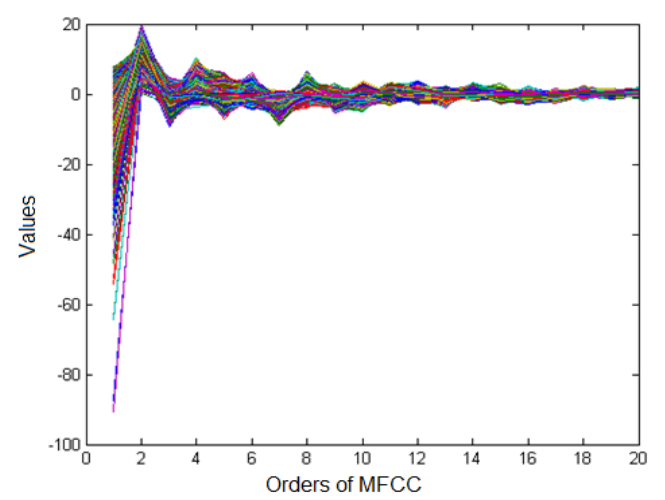

Fig. 3. Sample of MFCC file.

Feature extraction converts the input speech signal into a suitable feature space to be modelled. The first step of the proposed approach after extracting the features is to build a trained model. Since the proposed approach aims to identify the Holy Quran reader; samples from the Holy Quran recited aloud are required to build the corpus. An example of acoustic waves and their features is illustrated in Fig. 2 and Fig. 3 respectively. Acoustic waves for each reader, based on his readings, were collected. The feature vectors of these acoustic waves were extracted.

\section{A. Data Acquisition and Corpus Construction}

The Holy Quran is the Holy Scripture for Muslims as it is a comprehensive guide to a lifestyle based on what is written there. It is the collection of the verbal revelations given to Prophet Muhammad taught to believers over a period of twenty-three years. The Holy Quran was revealed in Arabic with 114 Chapters (Surahs) of varying lengths, and each Chapter consists of several individual verses (Ayaat). There are 6,348 different verses in the Holy Quran. To date, there is no corpus for the Ayaat of the Holy Quran based on their readers/reciters' performance. In this research we have chosen to segment two different Surahs, the first 120 Ayah from Suraht Al-Baqraa (chapter 1) as outlet data and Suraht Al Kahaf "سورة الكهف" (Chapter 18) into 110 separate Ayah for a specific reader as the corpus. In total, 15 different readers were considered for the corpus construction, as detailed in Table II. Each Holy Quran reader recites the 110 Ayah from Suraht Al Kahaf. A wave file was created for each Ayah. The total number of acoustic waves created is 1650 waves. The recognition system was implemented in MATLAB. The speech signal was divided into segments of $15 \mathrm{~ms}$ frames with the use of a Hamming window for further analysis. We experimentally determined that $15 \mathrm{~ms}$ frames generated better recognition because the Holy Quran readers generally have a slow rate of recitation. A larger frame size does not enhance the recognition system's ability to learn the characteristics of the signal.

TABLE II: HOLY QURAN READERS CITED IN STUDY

\begin{tabular}{|c|c|c|c|}
\hline Reader Name & $\begin{array}{l}\text { Arabic } \\
\text { Name }\end{array}$ & $\begin{array}{c}\text { Samples from } \\
\text { Al-Kahaf }\end{array}$ & $\begin{array}{c}\text { Samples from } \\
\text { Al-Baqara }\end{array}$ \\
\hline Mohammad Rashad. & محمد الراشد & 110 & 120 \\
\hline Maher Almuaiqly & ماهر المعيقلي & 110 & 120 \\
\hline Khaled Alqahtani & خالد القحطاني & 110 & 120 \\
\hline Ahmad Alhuthaifi & أحمد الحذيفي & 110 & 120 \\
\hline Ali Alhuthaifi & علي الحذيفي & 110 & 120 \\
\hline Ahmad Alajamy & أحمد العجمي & 110 & 120 \\
\hline Yahya Hawwa & يحبى حوى & 110 & 120 \\
\hline Abdullah Basfar & عبد الله بصفر & 110 & 120 \\
\hline Salah Albudair & صلاح البدير & 110 & 120 \\
\hline Yasser Aldosari & ياسر الدوسري & 110 & 120 \\
\hline Fares Abbad & فارس عباد & 110 & 120 \\
\hline $\begin{array}{l}\text { Abdulrahman } \\
\text { Alsudaes }\end{array}$ & عبدالرحمن & 110 & 120 \\
\hline Meshary Al-Afasy & مشاري العفاسي & 110 & 120 \\
\hline Saud Shuraim & سعود شريم & 110 & 120 \\
\hline Saad Alghamidi & سعد الغامدي & 110 & 120 \\
\hline
\end{tabular}

Since the Ayaat are of different lengths, a 20-feature representation of each Ayah was extracted for the 1650 acoustic waves as an MFCC file corresponding to the acoustic waves as discussed in Section III.B. Fig. 4 shows the feature vectors of the whole Ayaat.

Each ayah vector is transposed and labelled by the corresponding reader, as illustrated in Fig. 5. 


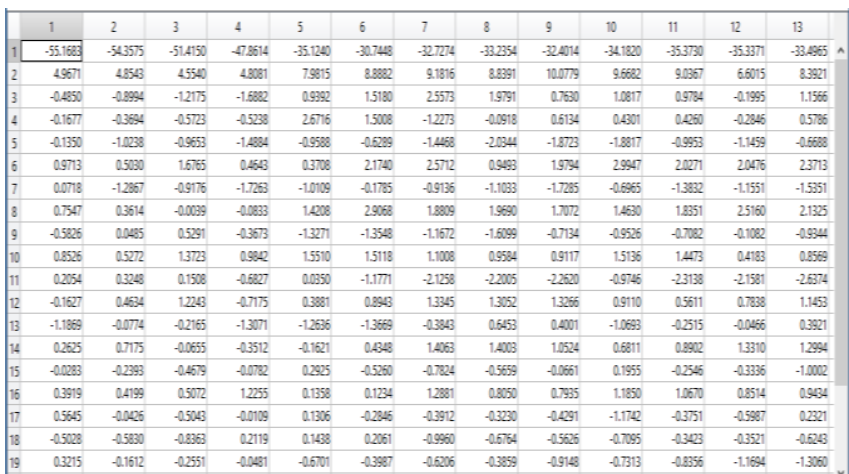

Fig. 4. Screnn shot of the feature vectors matrix of all readers $(20 * 22952)$.

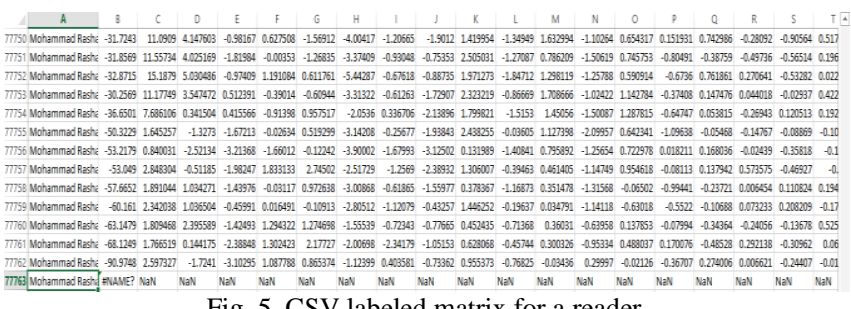

Fig. 5. CSV labeled matrix for a reader.

The 15- Feature Matrices were combined into one file for the 15 reader's features. For the purpose of training and testing, a WEKA tool was used with $70 \%$ to be in training as illustrated in Fig. 6 and 30\% for testing as illustrated in Fig. 7.

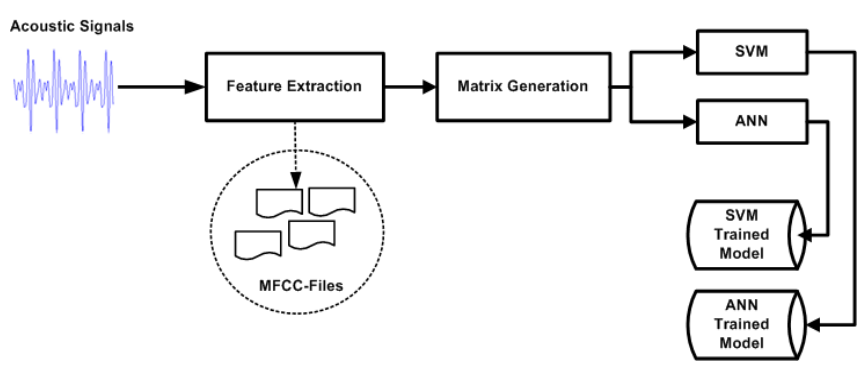

Fig. 6. $70 \%$ practice phase.

Moreover, a randomized filter property (from WEKA) was used for rearranging the features with randomly chosen rows. As can be seen from Fig. 6 for each sound wave the features were extracted and all features were combined in one labelled matrix. $70 \%$ of this matrix was to be inputted to both SVM and ANN to train the system. The result were two trained models one for SVM and one for ANN.

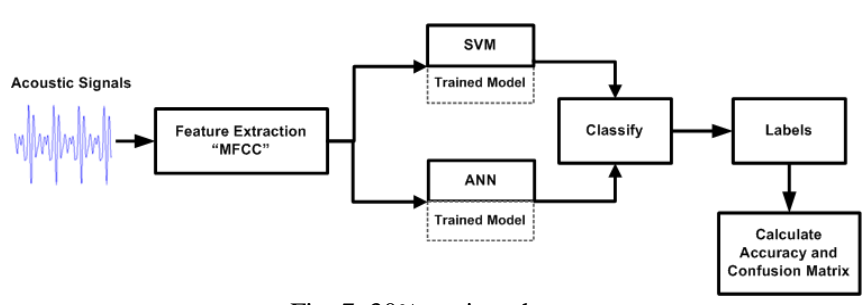

Fig. 7. 30\% testing phase.

After obtaining the trained models, the rest of the feature matrix (30\%) is used for testing them as seen in Fig. 7. The result of the test gave two confusion matrices one for SVM and one for ANN. The confusion matrix shows both the hit and miss classification of the waves. The correct classification is located on the main diagonal, while others are distributed up or down the main diagonal.

\section{B. Mel-Frequency Cepstrum Coefficients (MFCC)}

The Mel-Frequency Cepstrum Coefficients (MFCC) is a short-period power spectrum of sound wave representation. Mel frequencies are based on known variations in the human ear's critical bandwidth with frequency filters at frequencies below $1 \mathrm{kHz}$ and logarithmically at higher frequencies, to capture the phonetically important characteristics of speech [1]. In the Holy Quran, the correct form of pronunciation and voice depends on the context and is controlled by the reader's voice and his ability move from one pitch and tone to another (Maqam). The stages involved in Mel-frequency Cepstral Coefficient (MFCC) extraction are illustrated in Fig. 8.

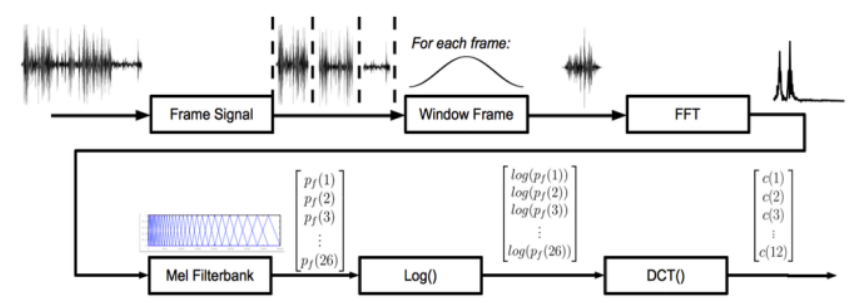

Fig. 8. MFCC feature extraction stages.

The MFCC is calculated using equation 1 and its implementation in Algorithm 1 [22].

$$
C_{i}=\sum_{k=1}^{N} X_{k} \cos \left(\frac{\left[\pi_{i}(k-0.5)\right.}{N}\right), \text { for } i=1,2, \ldots p
$$

where $C_{i}$ is the cepstral coefficients, $P$ is the order, $k$ is the number of discrete Fourier transforms magnitude coefficients, $X_{k}$ is the kth order log-energy output from the filter bank, and $N$ is the number of filters (usually 20). Thus, 19 coefficients and an energy feature were extracted, generating a vector of 20 coefficients per frame. In this research, the first 20-order of the MFCC were extracted.

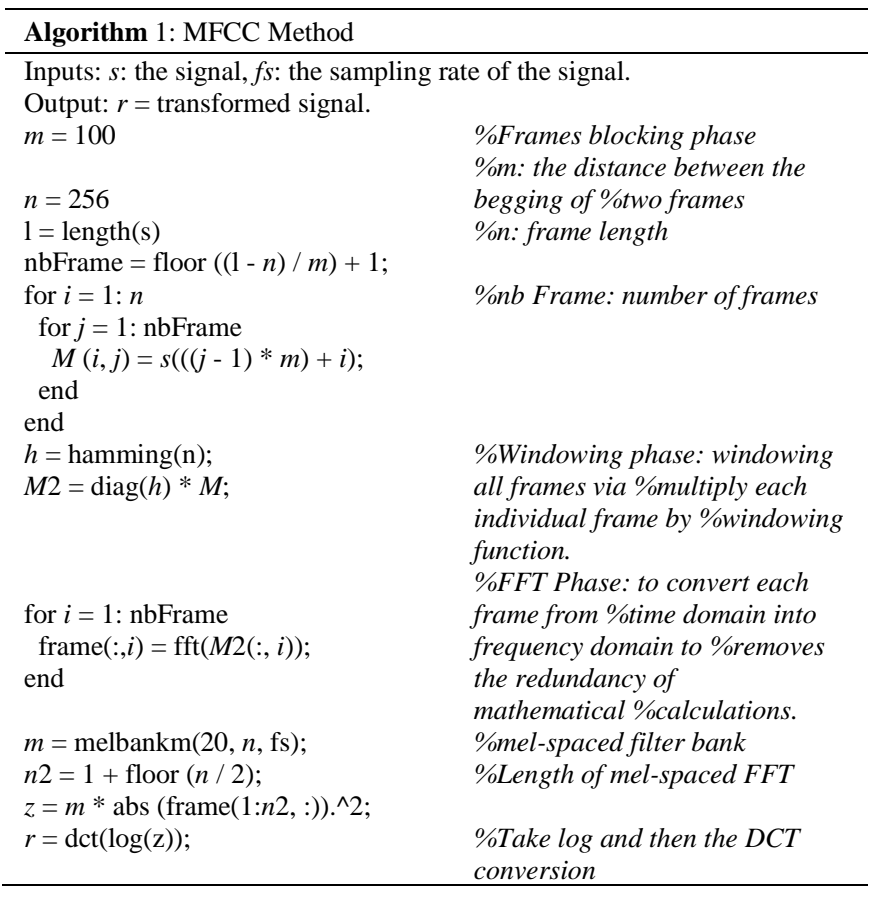

\section{Support Vector Machine}

A support vector machines (SVM) is a powerful and popular discriminative classifier. SVMs aim at maximizing the separation margin between two competing classes, where the margin is defined as the distance between the decision 
hyper plane and the closest training examples. In other words, finding the line that separates the sample into two classes with the maximum distance between the line and the samples. This line is called the hyper plane: the samples near the hyper plane are called support vectors. The maximum distance between the support vectors and the hyper plane is called the margin [2], [23]. Fig. 9 Is a simple pictorial view of SVM stages.

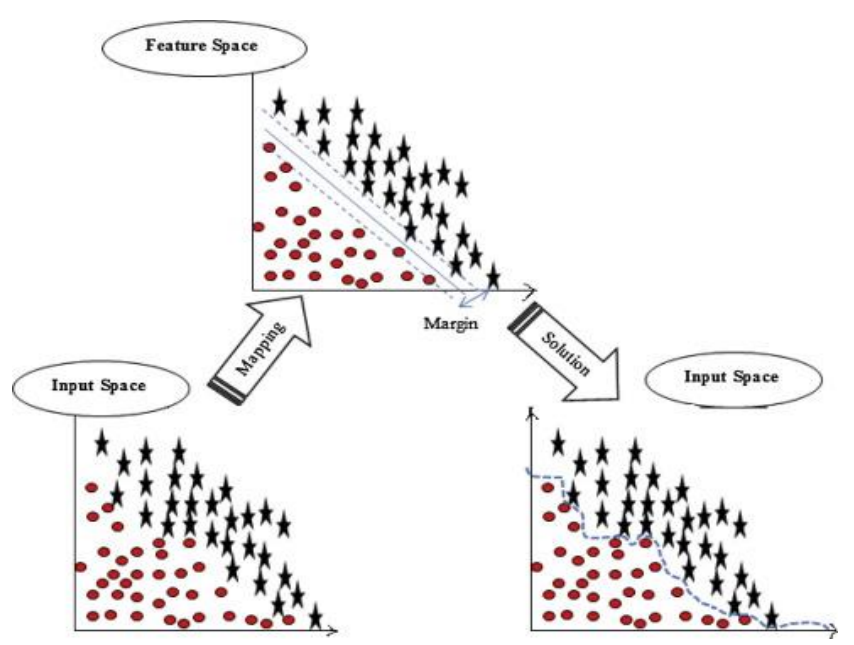

Fig. 9. SVM recognition stages [3].

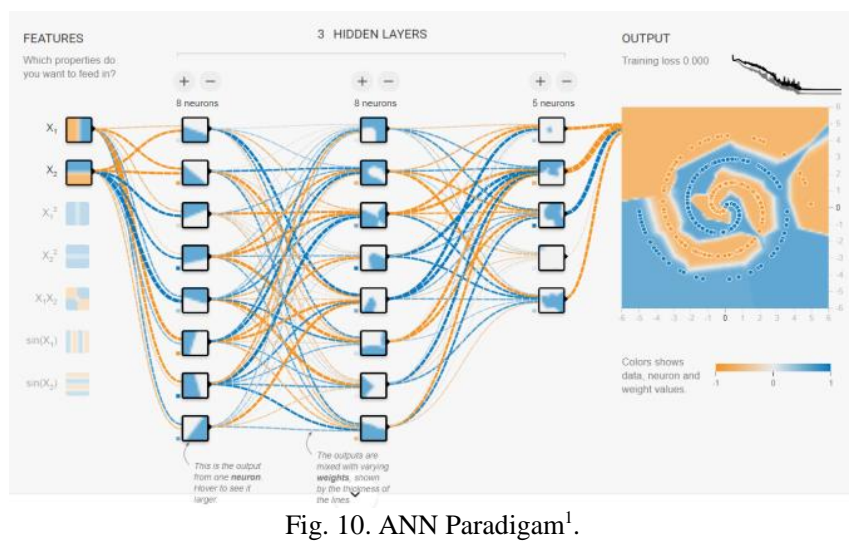

\section{Artificial Neural Networks}

Neural networks, a beautiful biologically-inspired programming paradigm which enables a computer to learn from observational data. It's a technique for building a computer program that learns from data. It is based very loosely on how we think the human brain works. First, a collection of software "neurons" is created and connected together, allowing them to send messages to each other. Next, the network is asked to solve a problem, which it attempts to do over and over, each time strengthening the connections that lead to success and diminishing those that lead to failure. Fig. 10 represent a simple ANN with one input layer, three hidden layers, and one output layer.

\section{EXPERIMENTS AND EVALUATION}

The Holy Quran Reader Identification system depends mainly on the features extracted from the acoustic waves, as

\footnotetext{
1 The picture is taken https://becominghuman.ai/creating-your-own-neural-network-using-tensorf low-fa8ca7cc4d0e
}

well as the learning and classification algorithms. The SVM is trained with the 15 readers of the Holy Quran in Table II. For comparison purposes, the same experiment was repeated with the ANN for classification. For training purposes, we have chosen $70 \%$ of the features for training in both SVM and ANN. The remaining $30 \%$ of the features is for the testing, as shown in Fig. 11.

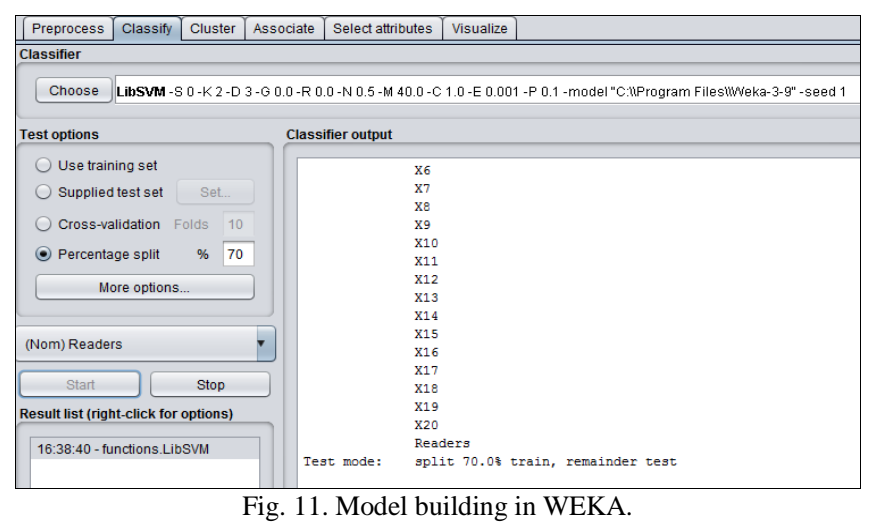

As shown in Fig. 11, X1, X2 up to X20 are the feature vector values or the predictors. The "Readers" are the target classes. After training the SVM over $70 \%$ of the features, it starts testing the trained model on $30 \%$. The result is a testing confusion matrix of the SVM. The confusion matrix is a data structure used to show the classification results. The rows of this matrix are the desired classification and the columns are the predicted classification.

Table III represents the confusion matrix of the testing phase with SVM. It is clear that some samples are below the hyper plane of the SVM (Main Diagonal) where others are above it. In both cases, it is considered a misclassification of the sample. The sample is correctly classified if it is on the main diagonal. In Table III, most of the samples are correctly classified. To calculate the accuracy, Eq (2) is used.

$$
\text { Accuracy }=\frac{\sum \text { DiagonalSample of confusion matrix }}{\text { TotalSample }}
$$

The overall accuracy of reader identification when using SVM is $96.59 \%$. About $4 \%$ of the total samples were misclassified. Although we generate samples from only one Surah, it was huge feature file to process. If the samples from Surah Al-Baqarah are entered as an outlet test data, the SVM shows $95.9 \%$ accuracy when tested by the outlet data from Al-Baqarah. The Differences between testing on test data from the same corpus (Surah Al-Kahaf) and the outlet data (Surah Al-Baqarah) is about $0.6 \%$, which is highly acceptable.

The misclassified samples were due to the way that the Holy Quran reader recited the different verses. The similarity between the reader's sound and the emotion expressed is critical. Especially since most of the Holy Quran readers follow the same reading rules "Ahkam Altajweed" when they are reciting the various verses of the chapter. Applying "Ahkam Altajweed" will increase the chance of the inter modulation between acoustic waves from different readers. Moreover, every reader has his own standard of delivery "Makam" (مقامات صوتية) which is often like that of other readers. 
TABLE III: TESTING CONFUSION MATRIX OF SVM

\begin{tabular}{|c|c|c|c|c|c|c|c|c|c|c|c|c|c|c|c|l|}
\hline 10 & 4 & 11 & 2 & 27 & 3 & 1 & 111 & 22 & 10 & 1 & 5 & 7 & 49 & 11181 & $\boldsymbol{o}=$ Fares Abbad \\
\hline 6 & 22 & 48 & 4 & 42 & 51 & 0 & 148 & 103 & 1 & 42 & 39 & 5 & 11136 & 60 & $\boldsymbol{n}=$ Yasser Aldosari \\
\hline 6 & 4 & 0 & 6 & 14 & 29 & 0 & 19 & 8 & 0 & 180 & 38 & 12740 & 20 & 1 & $\boldsymbol{m}=$ Mohammad Rashad \\
\hline 0 & 6 & 14 & 4 & 49 & 56 & 1 & 55 & 11 & 0 & 81 & 9136 & 24 & 51 & 10 & $\boldsymbol{l}=$ Salah Albudair \\
\hline 4 & 8 & 42 & 9 & 16 & 25 & 0 & 21 & 9 & 1 & 8726 & 75 & 193 & 41 & 0 & $\boldsymbol{k}=$ Saud Shuraim \\
\hline 6 & 7 & 6 & 0 & 1 & 4 & 15 & 3 & 3 & 6080 & 1 & 1 & 0 & 1 & 8 & $\boldsymbol{j}=$ Saad Alghamidi \\
\hline 30 & 10 & 6 & 8 & 15 & 12 & 1 & 138 & 10997 & 1 & 11 & 8 & 10 & 82 & 25 & $\boldsymbol{i}=$ Abdullah Basfar \\
\hline 12 & 19 & 35 & 36 & 28 & 27 & 0 & 12182 & 134 & 5 & 21 & 64 & 19 & 125 & 108 & $\boldsymbol{h}=$ Mishary Alafasi \\
\hline 3 & 2 & 1 & 0 & 0 & 1 & 4648 & 0 & 1 & 23 & 0 & 1 & 9 & 0 & 0 & $\boldsymbol{g}=$ Maher Almuaiqly \\
\hline 13 & 47 & 78 & 8 & 71 & 10195 & 0 & 51 & 15 & 4 & 46 & 112 & 55 & 62 & 15 & $\boldsymbol{f}=$ Alsudaes \\
\hline 2 & 116 & 77 & 9 & 10237 & 31 & 2 & 20 & 12 & 0 & 10 & 11 & 2 & 25 & 41 & $\boldsymbol{e}=$ Khaled Alqahtani \\
\hline 2 & 1 & 92 & 10307 & 5 & 12 & 0 & 50 & 3 & 0 & 10 & 5 & 2 & 7 & 0 & $\boldsymbol{d}=$ Yahiya Hawwa \\
\hline 17 & 29 & 10476 & 123 & 73 & 49 & 1 & 48 & 11 & 1 & 17 & 7 & 1 & 45 & 33 & $\boldsymbol{c}=$ Ahmad Alhuthaifi \\
\hline 7 & 10624 & 47 & 4 & 127 & 54 & 2 & 25 & 13 & 7 & 11 & 6 & 9 & 20 & 7 & $\boldsymbol{b}=$ Ahmad Alajamy \\
\hline 6225 & 2 & 21 & 4 & 6 & 10 & 0 & 23 & 41 & 2 & 4 & 2 & 0 & 4 & 20 & $\boldsymbol{a}=$ Ali Alhuthaifi \\
\hline $\boldsymbol{a}$ & $\boldsymbol{b}$ & $\boldsymbol{c}$ & $\boldsymbol{d}$ & $\boldsymbol{e}$ & $\boldsymbol{f}$ & $\boldsymbol{g}$ & $\boldsymbol{h}$ & $\boldsymbol{i}$ & $\boldsymbol{j}$ & $\boldsymbol{k}$ & $\boldsymbol{l}$ & $\boldsymbol{m}$ & $\boldsymbol{n}$ & $\boldsymbol{o}$ & \\
\hline
\end{tabular}

For comparison purposes, the same experiments were repeated with another learning algorithm, namely the ANN. The same files were used as an input to ANN with the same ratios of $70 \%$ for training and $30 \%$ for testing. The result shows that ANN converges and stops its progress when the accuracy reaches $86.17 \%$. The ANN confusion matrix is shown in. When feeding Surhat "Al-Baqara" as an outlet data for the ANN classifier, the percentage of accuracy fell to 83\%. The SVM shows superiority over ANN in this experiment. Table IV shows the summary of the results of the proposed system using SVM to contrast with ANN classifiers.

The SVM classifier shows a better result than ANN with our system. It has higher accuracy and lower MSE than ANN.

TABLE IV: SVM AND ANN RESULTS SUMMARY

\begin{tabular}{|l|l|l|}
\hline Accuracy / Learning Algorithm & SVM & ANN \\
\hline Accuracy-Normal Corpus & $96.59 \%$ & $86.17 \%$ \\
\hline Accuracy-Outlet Data & $95.9 \%$ & $83 \%$ \\
\hline Average Accuracy & 96.245 & 84.585 \\
\hline Average MSE & 0.0036 & 0.0144 \\
\hline
\end{tabular}

TABLE V: THE TEST CONFUSION MATRIX FOR ANN

\begin{tabular}{|c|c|c|c|c|c|c|c|c|c|c|c|c|c|c|c|}
\hline 75 & 20 & 77 & 5 & 112 & 4 & 6 & 252 & 81 & 49 & 0 & 25 & 15 & 100 & 10623 & $o=$ Fares Abbad \\
\hline 48 & 275 & 231 & 29 & 229 & 252 & 3 & 373 & 774 & 0 & 171 & 109 & 58 & 8661 & 494 & $n=$ Yasser Aldosari \\
\hline 46 & 27 & 9 & 34 & 217 & 158 & 9 & 114 & 102 & 9 & 434 & 302 & 11514 & 73 & 17 & $m=$ Mohammad Rashad \\
\hline 28 & 73 & 65 & 42 & 231 & 387 & 15 & 175 & 96 & 5 & 266 & 7696 & 150 & 151 & 118 & $l=$ Salah Albudair \\
\hline 73 & 82 & 150 & 115 & 154 & 181 & 7 & 70 & 89 & 6 & 7653 & 141 & 274 & 174 & 1 & $k=$ Saud Shuraim \\
\hline 37 & 68 & 6 & 5 & 8 & 9 & 152 & 27 & 47 & 5654 & 0 & 15 & 10 & 2 & 96 & $j=$ Saad Alghamidi \\
\hline 264 & 82 & 13 & 12 & 76 & 9 & 4 & 160 & 10406 & 22 & 7 & 38 & 31 & 185 & 45 & $i=$ Abdullah Basfar \\
\hline 218 & 127 & 101 & 95 & 144 & 72 & 1 & 10278 & 598 & 15 & 53 & 279 & 33 & 307 & 494 & $h=$ Mishary Alafasi \\
\hline 22 & 16 & 0 & 20 & 32 & 2 & 4242 & 14 & 5 & 287 & 4 & 27 & 17 & 0 & 1 & $g=$ Maher Almuaiqly \\
\hline 44 & 262 & 133 & 27 & 256 & 9102 & 13 & 51 & 152 & 10 & 96 & 241 & 153 & 140 & 93 & $f=$ Alsudaes \\
\hline 21 & 660 & 231 & 30 & 9208 & 84 & 5 & 53 & 62 & 1 & 49 & 28 & 9 & 26 & 128 & $e=$ Khaled Alqahtani \\
\hline 18 & 3 & 262 & 9908 & 79 & 9 & 3 & 97 & 27 & 2 & 42 & 9 & 6 & 23 & 8 & $d=$ Yahiya Hawwa \\
\hline 129 & 206 & 8833 & 967 & 244 & 165 & 25 & 44 & 63 & 11 & 13 & 32 & 12 & 73 & 114 & $c=$ Ahmad Alhuthaifi \\
\hline 33 & 9734 & 146 & 11 & 574 & 117 & 18 & 33 & 63 & 55 & 63 & 36 & 38 & 30 & 12 & $b=$ Ahmad Alajamy \\
\hline 5744 & 47 & 92 & 44 & 15 & 5 & 21 & 35 & 223 & 22 & 10 & 8 & 24 & 18 & 56 & $a=$ Ali Alhuthaifi \\
\hline$a$ & $b$ & $c$ & $d$ & $e$ & $f$ & $g$ & $h$ & $i$ & $j$ & $k$ & $l$ & $m$ & $n$ & $\boldsymbol{o}$ & \\
\hline
\end{tabular}

\section{CONCLUSION}

In this research, we developed a Holy Quran Reader Identification System from acoustic waves that represent the pronunciation of the "Ayaat". The MFCC features were extracted from the signals. The SVM and ANN classifiers were used, and their results were compared. The results obtained reveal that the identification accuracy using SVM is much better compared to the ANN. The SVM gives $96.59 \%$ accuracy while, $86.17 \%$ accuracy was obtained with ANN. The proposed system is the very first system for Holy Quran reader identification. In the future, we suggest extending our work with more than 15 Holy Quran readers and using further extraction techniques and classification algorithms such as the Gaussian Mixture, to increase the identification accuracy.

\section{ACKNOWLEDGEMENT}

We extend our sincere thanks to Yarmouk University - Irbid Jordan, where this scientific research was supported by the Deanship of Scientific Research and Graduate Studies at the University.

\section{REFERENCES}

[1] M. A. Islam, W. A. Jassim, N. S. Cheok, and M. S. A. Zilany, "A robust speaker identification system using the responses from a model of the auditory periphery," PLoS One, vol. 11, no. 7, p. e0158520, Jul. 2016.

[2] T. K. Das and K. M. O. Nahar, "A voice identification system using hidden markov model," Indian J. Sci. Technol., vol. 9, January 2016.

[3] S. B. Dhonde, A. Chaudhari, and S. M. Jagade, "Integration of mel-frequency cepstral coefficients with log energy and temporal derivatives for text-independent speaker identification," pp. 791-797, 2017.

[4] L. Bao and X. Shen, "Improved Gaussian mixture model and application in speaker recognition," in Proc. 2016 2nd International Conference on Control, Automation and Robotics (ICCAR), 2016, pp. 387-390.

[5] F. Meriem, H. Farid, B. Messaoud, and A. Abderrahmene, "New front end based on multitaper and gammatone filters for robust speaker verification," 2017, pp. 344-354.

[6] D. A. Reynolds, "Speaker identification and verification using Gaussian mixture speaker models," Speech Commun., vol. 17, no. 1-2, pp. 91-108, Aug. 1995.

[7] R. Hasan, M. Jamil, G. Rabbani, and S. Rahman, "Speaker Identification Using Mel Frequency Cepstral Coefficients," in Proc. $3 r d$ Int. Conf. Electr. Comput. Eng., pp. 28-30, December 2004.

[8] M. Jeevan, A. Dhingra, M. Hanmandlu, and B. K. Panigrahi, "Robust speaker verification using GFCC based i-vectors," 2017, pp. 85-91. 
[9] R. M. Fauzi and W. Maharani, "The recognition of hijaiyah letter pronunciation using mel frequency cepstral coefficients and hidden markov model," Adv. Sci. Lett., vol. 22, no. 8, pp. 2043-2046, Aug. 2016.

[10] S. Srivastava, M. Chandra, and G. Sahoo, Phase Based Mel Frequency Cepstral Coefficients for Speaker Identification, pp. 309-316, 2016.

[11] W. Fei, X. Ye, Z. Y. Sun, Y. J. Huang, X. Zhang, and S. X. Shang, "Research on speech emotion recognition based on deep auto-encoder," in Proc. 2016 IEEE International Conference on Cyber Technology in Automation, Control, and Intelligent Systems (CYBER), 2016, pp. 308-312.

[12] R. Saeidi, P. Alku, and T. Backstrom, "Feature extraction using power-law adjusted linear prediction with application to speaker recognition under severe vocal effort mismatch," IEEE/ACM Trans. Audio, Speech, Lang. Process., vol. 24, no. 1, pp. 42-53, Jan. 2016.

[13] L. Muda, M. Begam, and I. Elamvazuthi, "Voice recognition algorithms using Mel frequency cepstral coefficient (MFCC) and dynamic time warping (DTW) techniques," J. Comput., vol. 2, no. 3, pp. 2151-9617, 2010.

[14] T.-S. Chi, T.-H. Lin, and C.-C. Hsu, "Spectro-temporal modulation energy based mask for robust speaker identification," J. Acoust. Soc. Am., vol. 131, no. 5, p. EL368-EL374, May 2012.

[15] S. Nakagawa, L. Wang, and S. Ohtsuka, "Speaker identification and verification by combining MFCC and phase information," IEEE Trans. Audio. Speech. Lang. Processing, vol. 20, no. 4, pp. 1085-1095, May 2012.

[16] Y. Shao, Z. Jin, D. Wang, and S. Srinivasan, "An auditory-based feature for robust speech recognition," in Proc. 2009 IEEE International Conference on Acoustics, Speech and Signal Processing, 2009, pp. 4625-4628.

[17] R. Bharti and P. Bansal, "Real time speaker recognition system using MFCC and vector quantization technique," Int. J. Comput. Appl., vol. 117, no. 1, pp. 25-31, 2015.

[18] Y. Linde, A. Buzo, and R. Gray, "An algorithm for vector quantizer design,” IEEE Trans. Commun., vol. 28, no. 1, pp. 84-95, Jan. 1980.

[19] G. Nijhawan, "Speaker recognition using support vector machine," Int. J. Comput. Appl., vol. 87, no. 2, pp. 7-10, 2014.

[20] A. Mahmood, M. Alsulaiman, and G. Muhammad, "Automatic speaker recognition using multi-directional local features (MDLF)," Arab. J. Sci. Eng., vol. 39, no. 5, pp. 3799-3811, 2014.

[21] K. M. O. Nahar, M. Elshafei, W. G. Al-khatib, H. Al-muhtaseb, and M. M. Alghamdi, "Statistical analysis of arabic phonemes for continuous arabic speech recognition," Int. J. Comput. Inf. Technol., vol. 1, no. 2, pp. 49-61, 2012.

[22] S. A. Majeed, H. Husain, S. A. Samad, and T. F. Idbeaa, "Mel frequency cepstral coefficients (MFCC) feature extraction enhancement in the application of speech recognition: A comparison study," J. Theor. Appl. Inf. Technol., vol. 79, no. 1, pp. 38-56, 2015.

[23] W. S. Noble, "What is a support vector machine?" Nat. Biotechnol., vol. 24, no. 12, pp. 1565-1567, 2006.

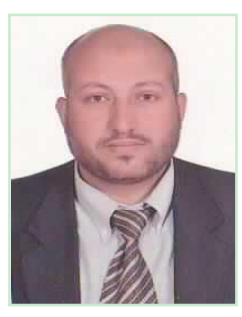

Khalid M. O. Nahar received his BS, and MS degrees in computer sciences from Yarmouk University in 1992 and 2005 respectively. He was awarded a full scholarship to continue his $\mathrm{PhD}$ in computer science and engineering from King Fahd University of Petroleum and Minerals (KFUPM), KSA. In 2013 he completed his PhD and started his job as an assistant Prof. at Tabuk University, from 2013 to 2015. In 2015, he back to work at Yarmouk University, Jordan, as an assistant professor in the
Department of Computer Science. For now, he is the dean assistant for quality control. His research interests include continuous speech recognition, Arabic computing, natural language processing, Wireless Sensor Networks (WSNs), multimedia computing, content-based retrieval, artificial intelligence, and software engineering.

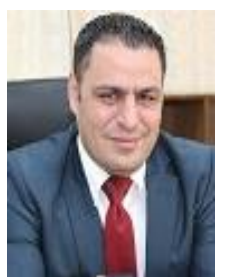

Moy'awiah Al-Shannaq is an assistant professor of computer sciences in the Faculty of Information Technology and Computer Science, Yarmouk University. Before joining Yarmouk University, Dr. Al-Shannaq has been working as a lecturer in the Department of Computer Sciences at Kent State University, Ohio, USA for two years. He received his MSc and BSc in computer sciences from Yarmouk University, Jordan. He received his $\mathrm{PhD}$ in computer sciences from Kent State University, Ohio, USA. His research interest include natural language processing, algorithmic graph and hypergraph theory, computational geometry, and network algorithms.

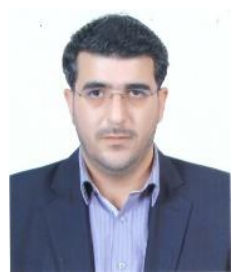

Ahmed M. Manasrah is an associate professor at Yarmouk University, Jordan since 2011, prior to joining Yarmouk University, Dr. Manasrah was the deputy director of research and innovation at the National Advanced IPv6 Center, Malaysia for 2 years. Dr. Manasrah has published over 40 international journal and 15 research papers including proceedings and 4 chapters of book, and 3 international patents in the field of network monitoring and security. Dr. Manasrah received his PhD from Universiti Sains Malaysia(USM) in 2009. His research interest includes advanced Internet security and monitoring.

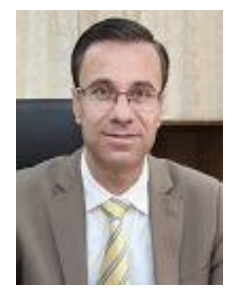

Rafat M. Alshorman is an assistant professor in the Department of Computer Science at Yarmouk University, Jordan. He completed his Ph.D. at Loughborough University, UK in 2009 and his undergraduate studies at Yarmouk University, Jordan. His research interests lie in the area of algorithms and mathematical models, ranging from theory to implementation, with a focus on checking the correctness conditions of concurrent and reactive systems. In recent years, he has focused on theoretical computer science such as graph theory and numerical analysis.

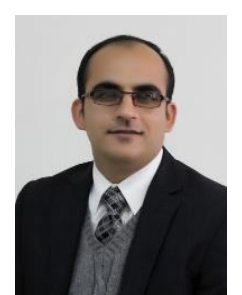

Iyad M Alazzam is an associate professor in the Department of Computer Information Systems at Yarmouk University in Jordan, he has received his $\mathrm{Ph} . \mathrm{D}$. degree in software engineering from NDSU (USA), He got his master degree in electronic Commerce from LMU (UK) and his BSc in computer science and information systems from Jordan University of Science and Technology. His research interests lay in software engineering and software testing and information retrieval. 